\title{
Commentary: The future fourth stage of single-ventricle palliation
}

\author{
Ryan R. Davies, MD
}

\footnotetext{
From the Department of Cardiovascular and Thoracic Surgery, UT Southwestern Medical Center and Children's Health, Dallas, Tex.

Disclosures: Author has nothing to disclose with regard to commercial support.

Received for publication July 23, 2019; accepted for publication July 25, 2019; available ahead of print Sept 10 , 2019.

Address for reprints: Ryan R. Davies, MD, 1935 Medical District Dr, MC B3.410, Dallas, TX 75235 (E-mail: ryan.davies@utsouthwestern.edu).

J Thorac Cardiovasc Surg 2019;158:1639-40

$0022-5223 / \$ 36.00$

Copyright (C) 2019 by The American Association for Thoracic Surgery

https://doi.org/10.1016/j.jtcvs.2019.07.077
}

Five decades after Francis Fontan first described his procedure for palliation of tricuspid atresia, modified versions have enabled long-term survival of a broad array of patients with univentricular circulation. ${ }^{1}$ It has long been recognized, however, that the sequelae of the total cavopulmonary connection-including systemic venous congestion, hepatic dysfunction, renal insufficiency, changes in pulmonary vascular physiology, and elevated systemic afterload-result in long-term failure of even the "perfect" Fontan circulation. ${ }^{2,3}$ Transplantation provides a pathway out of the spiral of heart failure and end-organ dysfunction, leading Michielon and colleagues ${ }^{4}$ to call it the "fourth stage" of univentricular palliation. Unfortunately, at the time of evaluation, the slow but steady accumulation of end-organ injury often limits transplant candidacy. ${ }^{5}$

Prevention of end-organ injury has the potential to alter dramatically the long-term prognosis of Fontan palliation. The pump described by Rodefeld and colleagues ${ }^{6}$ in this issue of the Journal provides one potential pathway to reducing the negative impact of the Fontan circulation. Placed within the Fontan circuit, its goal is to reduce central venous pressures sufficiently to eliminate the Fontan paradox of coexistent elevations in systemic venous pressure and reduced cardiac output. Although the pump is still at the early (preimplant) stages of development, Rodefeld and colleagues ${ }^{6}$ have identified many of the characteristics that will be required for effective and safe long-term mechanical support of the Fontan circulation. In a simulated circulation, the pump appears to provide effective pressure and flow augmentation, with acceptable shear stress and heat dissipation. Importantly, pump failure results in unobstructed Fontan flow. As Rodefeld and colleagues ${ }^{6}$ note, this is critical to the long-term safety profile of a pump used for augmentation of the cavopulmonary circulation.

As Rodefeld moves toward implantation of the device, the first barrier to be crossed will be the effectiveness of the pump. The challenges of pump implantation and the move from in vitro to in vivo success are not

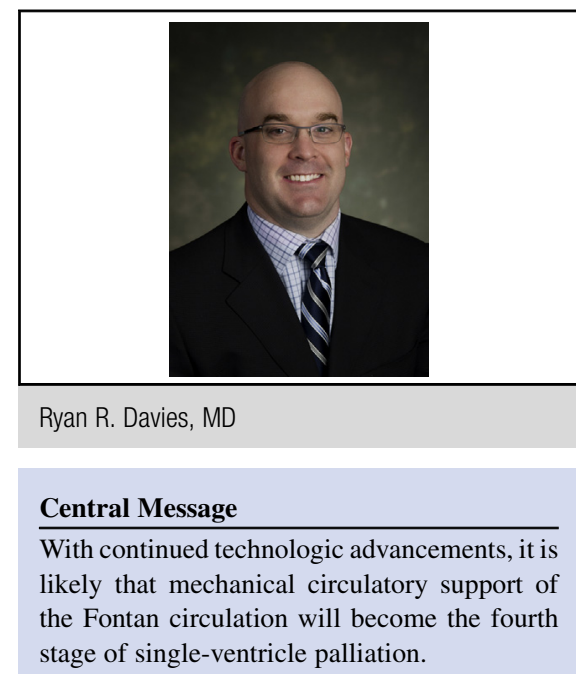

See Article page 1627.

straightforward. Furthermore, even if the pump achieves its predicted in vivo hemodynamic improvements, the impact on Fontan failure are uncertain. Many of the complications of the Fontan circulation, including lymphatic abnormalities and progression of hepatic dysfunction, are poorly correlated with measured Fontan pressures. Whether lowering those pressures in an individual patient will have salutary effects and cure the Fontan paradox remains uncertain.

Uncertainty also surrounds the effects of augmented, but still nonpulsatile, pulmonary arterial flow. The degree to which pulmonary vascular abnormalities arising from the Fontan circulation are the result of passive low-pressure flow versus the absence of pulsatility is completely unknown. It is possible that even with augmented flow, progressive pulmonary vascular disease will result from the lack of pulsatility. Despite these unanswered questions, the pump developed by Rodefeld and his team displays early promise, and clinical implantation is likely to be the only path to full understanding of the impact of augmented but still nonpulsatile pulmonary flow on the Fontan circulation.

Although the current pathway of single-ventricle palliation with culmination in the third-stage Fontan procedure has provided a large number of patients with the opportunity to live into adulthood with only one effective ventricle, as these patients get older, its limitations become clearer. Transplantation has provided a fourth stage of palliation, but it has only limited availability. It is likely that with 
advances in technology and pumps specifically designed for the Fontan circulation mechanical circulatory support will provide a more widely available fourth stage of palliation, enabling long-term survival into adulthood with preserved end-organ function. ${ }^{7}$ Rodefeld's pump is an early but important step toward the future of fourth-stage palliation for patients with single-ventricle circulation.

\section{References}

1. Fontan F, Baudet E. Surgical repair of tricuspid atresia. Thorax. 1971;26:240-8.

2. Fontan F, Kirklin JW, Fernandez G, Costa F, Naftel DC, Tritto F, et al. Outcome after a "perfect" Fontan operation. Circulation. 1990;81:1520-36.
3. Pundi KN, Johnson JN, Dearani JA, Pundi KN, Li Z, Hinck CA, et al. 40-year follow-up after the Fontan operation: long-term outcomes of 1,052 patients. J Am Coll Cardiol. 2015;66:1700-10.

4. Michielon G, van Melle JP, Wolff D, Di Carlo D, Jacobs JP, Mattila IP, et al. Favourable mid-term outcome after heart transplantation for late Fontan failure. Eur J Cardiothorac Surg. 2015;47:665-71.

5. Crossland DS, Jansen K, Parry G, Harper A, Perri G, Davidson A, et al. Outcome following heart transplant assessment in adults with congenital heart disease. Heart. July 5, 2019 [Epub ahead of print].

6. Rodefeld MD, Marsden AL, Figliola R, Jonas T, Neary M, Giridharan GA. Cavopulmonary assist: long-term reversal of the Fontan paradox. J Thorac Cardiovasc Surg. 2019;158:1627-36.

7. Jaquiss RD, Aziz H. Is four stage management the future of univentricular hearts? Destination therapy in the young. Semin Thorac Cardiovasc Surg Pediatr Card Surg Annu. 2016;19:50-4. 